\title{
Mitteilung der Herausgeber
}

Heinz Wenzel ist aus dem Herausgebergremium ausgeschieden. Neu eingetreten sind Josef Simon (Bonn) und Jörg Salaquarda (Wien). Die Redaktion leitet von diesem Band an Kurt Dite (Wien). Dem bisherigen Redaktionsteam - Wilhelm Haumann, Gerburg Lindner und Hays Steilberg beim Lehrstuhl von Eckhard Heftrich in Münster - sei für die geleistete Arbeit herzlich gedankt. Marie-Luise Haase (Weimar) und Martin Stingelin (Basel) unterstützen Herausgeber und Redaktion bei der Betreuung der von Montinari angeregten Abteilung Quellenforscbung.

In Bd. 20/1991 (S. 314-328) des Jabrbuchs hat Reinhard Brandt einen Beitrag über „Die Titelvignette von Nietzsches Geburt der Tragödie aus dem Geiste der Musik" veröffentlicht. Durch ein bedauerliches Versehen ist es versäumt worden, die in dem Aufsatz behandelte Vignette mit abzudrucken. Im Zusammenhang mit Siegfried Mandels Artikel „Genelli and Wagner: Midwives to Nietzsche's The Birth of Tragedy" ist allerdings bereits in Band 19/1990 eine vergrößerte Version der Vignette wiedergegeben worden (S. 229).

Wir bitten Sie, Manuskripte in Zukunft an die Redaktion in Wien zu senden und sich auch mit Anfragen dorthin zu wenden. Zur Zeit wird ein Gesamtregister zu den Bänden 1-20 der Nietzsche-Studien erarbeitet, das demnächst erscheinen wird. 
